\title{
HULA: Hotspot User Locator Application
}

Lourence R. Villaluz

Department of Information Technology, Eastern Samar State University, Borongan City, Eastern Samar, Philippines; rhencerivillaluz@gmail.com

\begin{abstract}
Objective: The primary aim of this study is to develop a mobile application capable of measuring Wi-Fi signal strength from any unsecured Wi-Fi hotspot that may possibly come from a possible victim in a collapsed structure. Methods and Statistical Tools: The researcher followed the iterative development model as its primary framework in the development of the application. The researcher utilized the IBM computer usability scale as its primary usability evaluation tool. Findings: The researcher was able to successfully develop the application and was able to read Wi-Fi signals from nearby devices. Applications/Improvements: The application can be utilized by search and rescue officials to locate possible victims on a collapsed building after an earthquake by determining the location of the Wi-Fi signal being read the application.
\end{abstract}

Keywords: Android, Disaster, Mobile Application, Rescue, Search, WiFi

\section{Introduction}

Natural disasters are inevitable in this world we cannot deny the fact that these kinds of disasters exist and it is a threat to humankind. This includes typhoons, volcanic eruptions, floods, tsunamis, and earthquakes. Countless individuals around the globe suffer and die in such catastrophes every year.

The geographical location and physical environment of the Philippines were the reasonswhy it is vulnerable to many types of natural hazards. Being located in the Pacific Ring of Fire where recurrent earthquakes and volcanic activity is caused by the movement of the two Tectonic plates, Eurasian and Pacific ${ }^{1}$.

Everyday earthquakes are being recorded by the PHilippine Institute of VOLCanology and Seismology (PHIVOLCS) a service institute of the Department Of Science and Technology (DOST) that is responsible for detecting volcanic and seismic activity ${ }^{2}$. The average that the Philippines experiences are 20 earthquakes per day, but most of them are too weak to be felt.Sometimes earthquake can be destructive when it becomes too strong, it can damage properties and infrastructures, cause injury, immense loss of life and trap people in the debris.
A lot of efforts have been made to better understand earthquake processes around the world, preparing for earthquakes and associated hazards can help the public effectively, and lessen the damages of the earthquakes.

The search and rescue operation must always be prepared in case a destructive earthquake occurs. The most complicated and hard to do in search and rescue operations is locating a potential victim in a collapsed structure. Search and rescue operations for initial lifesaving must arrive very fast, rescuers must possess specialized skills, and specialized technical equipment.

The City Disaster Risk Reduction and Management Office (CDRRMO) is a government office for disaster planning, preparation, mitigation, and search and rescue of the Borongan city. They lack proper equipment for search and rescue and only have few rescuers. They conduct drills to the different barangays, in case an earthquake occurs in the city, the barangays can be the first responder. The earthquake can cause widespread damage and if the office will only do the work then they cannot handle it due to their current problem in manpower and equipment.

Emergency and disaster management has increasingly driven by mobile phone technology not 
only communication. Mobile phones are fast emerging as being so much more than just communication tools, they are progressively being used to book an appointment, to transfer cash, ordering pizza or paying bills, and among other examples. Now, with the rise of catastrophic events mobile phones have evolved from an expensive gadget to a lifesaver technology. Mobiles are likely to be the dominant means of communication for [disaster] affected members of the public ${ }^{3}$.

Wireless Fidelity (Wi-Fi) on the other hand, has become near ubiquitous in homes, workplaces, and public spaces. Wi-Fi applies to any product that can support Wireless Local Area Networks (WLAN), including mobile phones, laptops, tablet computers, and among others. With the prevalent adoption of wireless technology in almost every aspect of modern life, why not use this as a means for helping people in disasters.

Hence, with the presence of mobile phones and Wi-Fi technology, the researcher came up with an idea of a system that can support the search and rescue effort of the CDRRMO rescuers. A search and rescue tool entitled HULA: Hotspot User Locator Application, the HULA isa mobile application developed to be an instrument to measure the Wi-Fi signal strength from any unsecured Wi-Fi hotspot that may possibly come from a possible victim in a collapsed structure. The HULA scans all the available Wi-Fi present in the area and connects to a desired Service Set IDentifier (SSID) name. This allowed the CDRRMO rescuers to immediately respond in an earthquake based scenario.

\section{Objectives of the Study}

This study aimed to develop a mobile application entitled HULA: Hotspot User Locator Application that serves as a tool in locating possible victims' location. Specifically, the study aimed to:

1. Develop a mobile application that scans all available Wi-Fi networks in the area.

2. Develop a mobile application that measures the signal strength of a Wi-Fi hotspot.

3. Develop a Wireless Local Area Network (WLAN) based search and rescue tool.

4. Evaluate using the expert and end users test based on IBM Computer System Usability Scale.

\section{System Development Model}

The researcher used the iterative development model for this study. The full system was started, but there were changes in functionality for every new version that was released, there were a total of 9 versions created. All features are there but there are still functions need to improve over iterations.

Figure 1 shows the different phases that the systems undergo to be developed and completed. The researcher used the iterative model because just like any other mobile applications, the researcher can put improvements by releasing new versions and it allows the developers to fix unexpected problems quickly.

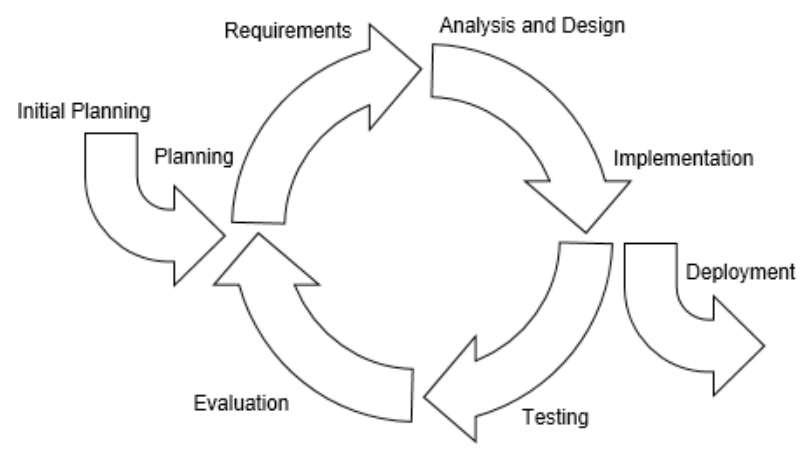

Figure 1. Iterative development.

\section{Planning and Requirements}

Just like any other development model, the researcher did initial planning to map out the requirement documents, and established software and hardware requirements, and prepare for upcoming phases of the cycle. The researchers' crutinized the problem and collect vital information through conducting an interview at the CDRRMO and conducted research to be able to create solutions. Requirements for software development were also gathered by the researcher.

\section{Analysis and Design}

After the researcher completed the planning phase, the researcher developed an initial design of the system. But over the iterations, the designs become more detailed until it gave the researcher much more constant structure. 


\section{Implementation}

The researcher started the process of coding the initial designs. The initial iteration was started here.

\section{Testing}

The designs are coded, the researcher stepped through a sequence of test process and the issues of the system has been identified and traced, the researcher returned to check the requirements. The process repeated and got the desired framework design.

\section{Evaluation}

In this phase, the researcher conducted an evaluation of the system after all the phases have been completed. This allowed the CDRRMO personnel to examine the system. The feedback and changes in this phase were brought back to the planning phase, the process repeated all over again and the researcher got the accurate system.

The Figure 2 shows the general flow of transactions of the systems from the users.

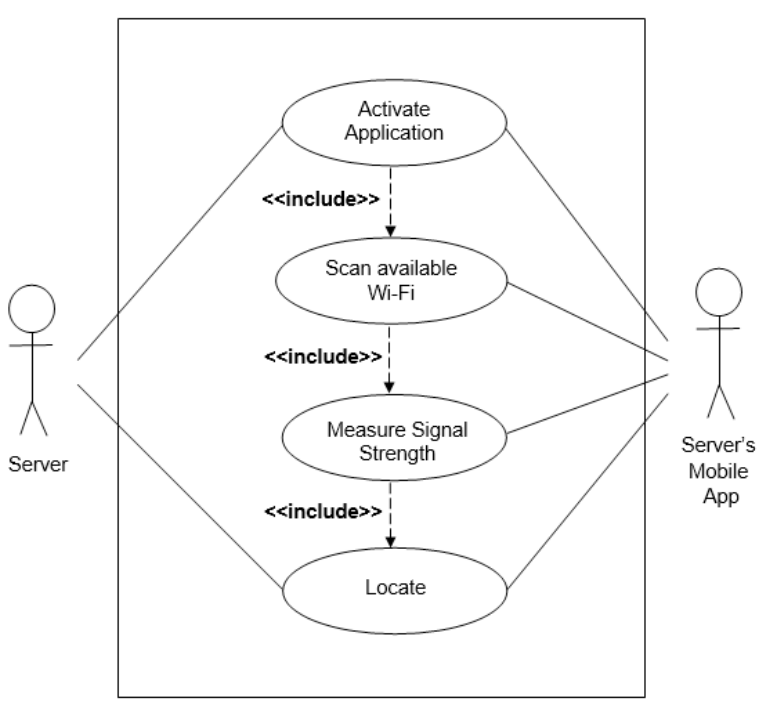

Figure 2. Use case diagram.

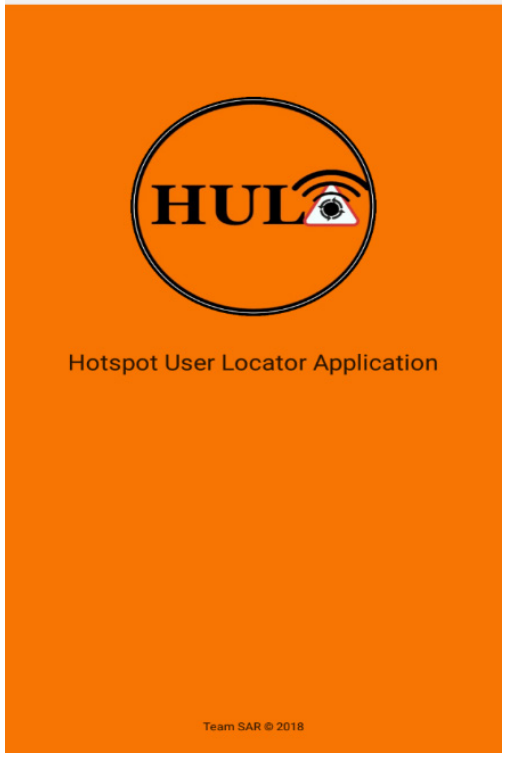

Figure 3. Splash screen.

\section{Output and User Interface}

The Output and User Interface are the graphical design of the system which the end user interacts with. This is displayed after the user opens the application. Once the Wi-Fi scan button is tap, the application will display all the available Wi-Fi hotspot networks that are in its area. The rescuer can now select the desired SSID name as shown in Figure 4.

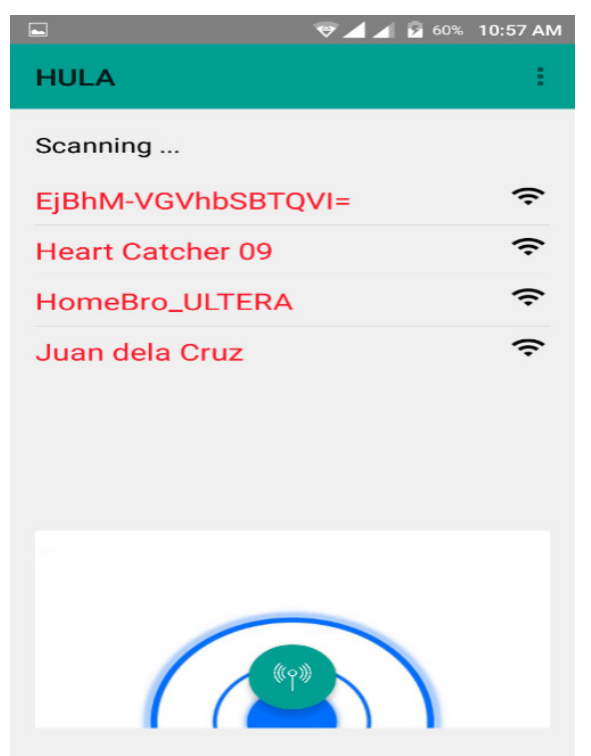

Figure 4. Scan activity. 
After the user selected the desired Wi-Fi network, connect to a network dialog box will appear toconnect and cancel button as shown in Figure 5. This displays the signal strength of the Wi-Fi hotspot with the SSID name after being connected to the desired Wi-Fi hotspot as shown in Figure 6.

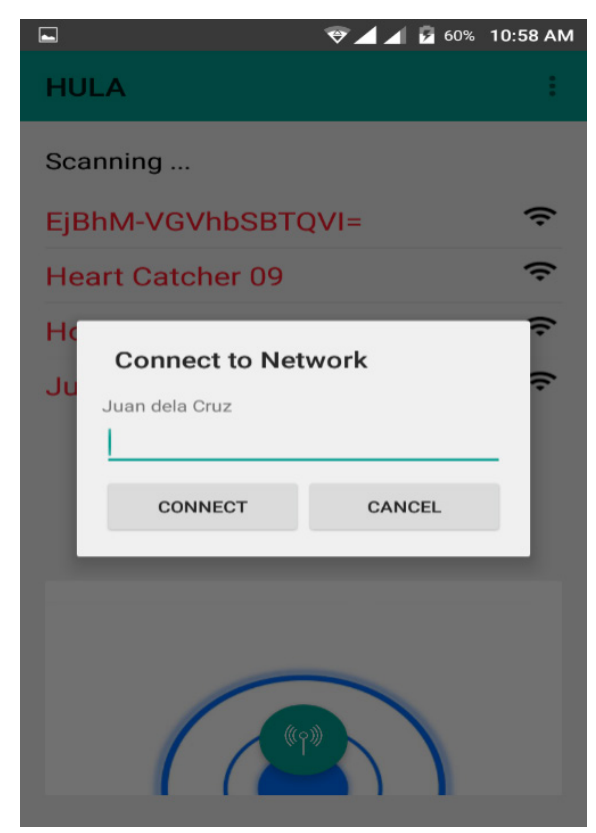

Figure 5. Connect to network.

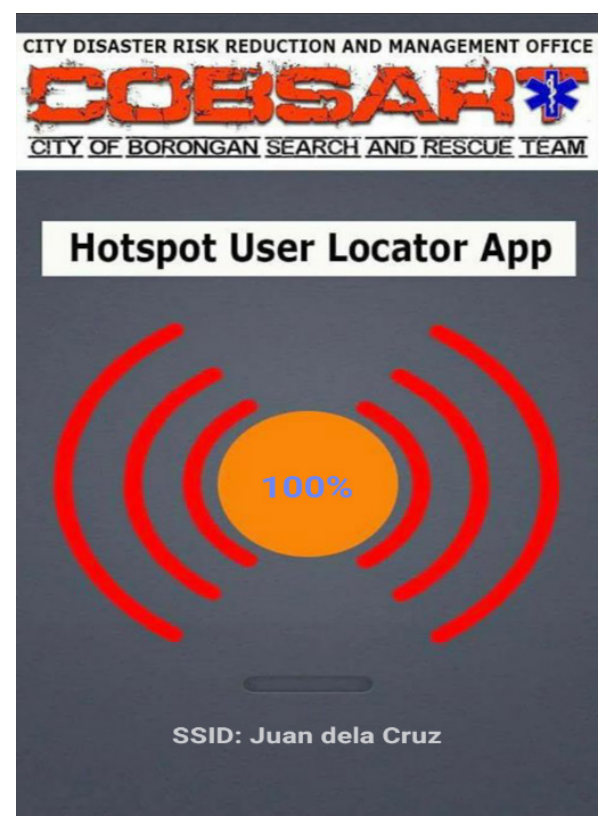

Figure 6. Signal strength activity.

\section{Expert Testing}

The researcher invited a pool of experts composed of 5 faculty members of the College of Computer Studies to evaluate the developed system. The experts were chosen based on their expertise in android development and mobile technology in general. The experts used the IBM Computer System Usability Scale in evaluating the system.

After the system was developed, a field of the test was conducted in order to verify the system's satisfaction for the intended users. The expert test resulted in a grand mean of 4.51 interpreted as highly usable in Table 1. Some questions got the lowest weighted mean but still interpreted as highly usable. The highest weighted mean of 4.8 is interpreted as highly usable, this is because the system is very easy to use and simple, but can have a big impact in search and rescue situation. In overall evaluation, the interpretation shows that the system corresponds to the IBM Computer System Usability Scale.The positive results of the test from experts and is inconsonance with the research ofUniversidad de Alicante according to R\&I World, 2017 says that it is possible to find individuals who have endured in remote areas without a phone signal and where a quick rescue is essential to spare lives.

Table 1. Weighted mean for the expert test

\begin{tabular}{|l|c|c|}
\hline \multicolumn{1}{|c|}{ Questions } & $\begin{array}{c}\text { Weighted } \\
\text { Mean }\end{array}$ & $\begin{array}{c}\text { Adjectival } \\
\text { Interpretation }\end{array}$ \\
\hline $\begin{array}{l}\text { Overall, I am satisfied with how } \\
\text { easy it is to use this system. }\end{array}$ & 4.6 & Highly Usable \\
\hline It was simple to use this system. & 4.8 & Highly Usable \\
\hline $\begin{array}{l}\text { I could effectively complete the } \\
\text { tasks and scenarios using this } \\
\text { system. }\end{array}$ & 4.6 & Highly Usable \\
\hline $\begin{array}{l}\text { I was able to complete the tasks } \\
\text { and scenarios quickly using } \\
\text { this system. }\end{array}$ & 4.8 & Highly Usable \\
\hline $\begin{array}{l}\text { I was able to efficiently } \\
\text { complete the tasks and } \\
\text { scenarios using this system. }\end{array}$ & 4.6 & Highly Usable \\
\hline $\begin{array}{l}\text { I felt comfortable using this } \\
\text { system. }\end{array}$ & 4.2 & Highly Usable \\
\hline $\begin{array}{l}\text { It was easy to learn to use this } \\
\text { system. }\end{array}$ & 4.2 & Highly Usable \\
\hline $\begin{array}{l}\text { I believe I could become } \\
\text { productive quickly using this } \\
\text { system. }\end{array}$ & 4.2 & Highly Usable \\
\hline
\end{tabular}




\begin{tabular}{|l|c|l|}
\hline $\begin{array}{l}\text { The information (such as on- } \\
\text { line help, on-screen messages } \\
\text { and other documentation) } \\
\text { provided with this system was } \\
\text { clear. }\end{array}$ & 4.4 & Highly Usable \\
\hline $\begin{array}{l}\text { It was easy to find the } \\
\text { information I needed. }\end{array}$ & 4.4 & Highly Usable \\
\hline $\begin{array}{l}\text { The information provided } \\
\text { for the system was easy to } \\
\text { understand. }\end{array}$ & 4.4 & Highly Usable \\
\hline $\begin{array}{l}\text { The information was effective } \\
\text { in helping me complete the } \\
\text { tasks and scenarios. }\end{array}$ & 4.6 & Highly Usable \\
\hline $\begin{array}{l}\text { The organization of } \\
\text { information on the system } \\
\text { screens was clear. }\end{array}$ & 4.8 & Highly Usable \\
\hline $\begin{array}{l}\text { The interface of this system was } \\
\text { pleasant. }\end{array}$ & 4.4 & Highly Usable \\
\hline $\begin{array}{l}\text { I liked using the interface of } \\
\text { this system. }\end{array}$ & 4.6 & Highly Usable \\
\hline $\begin{array}{l}\text { This system has all the } \\
\text { functions and capabilities I } \\
\text { expect it to have. }\end{array}$ & 4.4 & Highly Usable \\
\hline $\begin{array}{l}\text { Overall, I am satisfied with this } \\
\text { system. }\end{array}$ & 4.6 & Highly Usable \\
\hline
\end{tabular}

\begin{tabular}{|l|l|l|}
\hline Grand Mean & 4.51 & Highly Usable \\
\hline
\end{tabular}

\section{Conclusion}

With the aim of the researcher to help the search and rescue operations of CDRRMO officials of Born-again city after the onslaught of natural calamities, an instrument capable of measuring the Wi-Fi signal strength from any unsecured Wi-Fi hotspotwas developed. The HULA scans all the available Wi-Fi present in the area and connects to a desired SSID name. The systems overall usability was evaluated using the IBM computer usability scale. The evaluation resulted in a grand mean of 4.51 interpreted as highly usable. This infers that the CDRRMO officials, which acted as end-user testers, were able to use the system with ease was able to accomplish their tasks using the system.

\section{References}

1. Orallo A.-D. Study on Earthquake Risk and Vulnerability Management and Lessons Learned. The Philippine Disaster Management System; 2011. p. 1-67.

2. PHIVOLCS. Date accessed: 08.05.2008. http://www. phivolcs.dost.gov.ph, http://www.phivolcs.dost.gov.ph/ index.php?option=com_content\&view=article\&id=13\&Ite $\operatorname{mid}=19$.

3. Coyle D. The role of Mobiles in Disasters and Emergencies. London, UK: GSM Association; 2005. p. 1-40. 